\title{
The Effect of Tool Construction and Cutting Parameters on Surface Roughness and Vibration in Turning of AISI 1045 Steel Using Taguchi Method
}

\author{
Rogov Vladimir Aleksandrovich, Ghorbani Siamak \\ Department of Engineering Technology, Machine Tools and Metal-Cutting Tools and Instruments, \\ People's Friendship University of Russia, Moscow, Russia \\ Email: siamak_1997@yahoo.com
}

Received November 15, 2013; revised December 29, 2013; accepted January 12, 2014

Copyright (C 2014 Rogov Vladimir Aleksandrovich, Ghorbani Siamak. This is an open access article distributed under the Creative Commons Attribution License, which permits unrestricted use, distribution, and reproduction in any medium, provided the original work is properly cited. In accordance of the Creative Commons Attribution License all Copyrights (C) 2014 are reserved for SCIRP and the owner of the intellectual property Rogov Vladimir Aleksandrovich, Ghorbani Siamak. All Copyright (C) 2014 are guarded by law and by SCIRP as a guardian.

\begin{abstract}
This paper presents an experimental investigation focused on identifying the effects of cutting conditions and tool construction on the surface roughness and natural frequency in turning of AISI1045 steel. Machining experiments were carried out at the lathe using carbide cutting insert coated with TiC and two forms of cutting tools made of AISI 5140 steel. Three levels for spindle speed, depth of cut, feed rate and tool overhang were chosen as cutting variables. The Taguchi method $L_{9}$ orthogonal array was applied to design of experiment. By the help of signal-to-noise ratio and analysis of variance, it was concluded that spindle speed has the significant effect on the surface roughness, while tool overhang is the dominant factor affecting natural frequency for both cutting tools. In addition, the optimum cutting conditions for surface roughness and natural frequency were found at different levels. Finally, confirmation experiments were conducted to verify the effectiveness and efficiency of the Taguchi method in optimizing the cutting parameters for surface roughness and natural frequency.
\end{abstract}

\section{KEYWORDS}

Surface Roughness; Cutting Condition; Natural Frequency; Vibration; Turning; ANOVA; Taguchi Method; S/N Ratio

\section{Introduction}

One of the most fundamental metal removal operations used in manufacturing industry is turning, which is done with a long and slender tool so that it can fit into or through complex workpiece geometry. Machining depends on many factors such as machine rigidity, fixing rigidity, tool rigidity, good vibration damping capability and rigidity of component parts [1]. Surface roughness is one of the important aspects in mechanical design, since it dominates the requirements of many mechanical parts such as wear and corrosion resistances, fatigue strength, product life and heat generation. Chatter vibrations occurring in turning operation create large cutting forces, which can damage the machine, cutting tool and workpiece, consequently, causing tool wear, tool breakage, unacceptable surface finish and dimensional errors [2,3]. For this reason, avoidance of chatter vibrations is crucial. Besides, turning operation contains many parameters such as workpiece and cutting tool materials, feed rate, spindle speed, depth of cut, coolant, tool construction, tool overhang, tool nose radius and tool edge angles. Therefore, it is difficult to achieve the required surface quality [4-6]. However, severe chatter vibrations occur in turning operation due to a dynamic motion between the work piece and the cutting tool [7-9].

From the literature review of vibration induced by a machining process, clearly the majority of works attempt to reduce vibration during machining process. The aim of vibration reduction is to increase dynamic stiffness of machining system or change its main natural frequency or feedback-controlled actuators, which can be achieved 
by using a vibration damper, applying a special coating on a cutting insert or using a toolholder made of material with a high damping capability [10]. Kanase and Jadhav [11] and Abuthakeer et al. [12] used a passive damping pad of viscoelastic material of neoprene and a passive vibration damping in their investigations to predict and suppress the vibration level of cutting tool. They found that impact damping has improved the surface finish in machining operation. Devin and Osadchii [13] proposed a new tool design with an increased vibration-damping ability, which includes special elements made of damping materials to reduce vibration amplitude and surface roughness. Sortino et al. [14] studied the influence of the material and geometry of the tool and workpiece on process stability in internal finish turning. They found that the ratio of boring bar overhang to bar external diameter has a significant effect on the stability of the process. Kopač et al. [15] performed an investigation on identification of the dynamic instability in hard turning process based on the determination of natural frequencies of machine tool components on different positions in work area and position of resonance frequency determination. The results showed that if cutting instability and push-off effect do not have dominant influence, it is possible to achieve minimum roughness on machined surface. Mustafa and Emre [16] evaluated the effects of cutting parameters on surface roughness and found the optimal cutting parameter levels in turning of Ni-Hard (62 HRC and 50 HRC) by using statistical methods of signal to noise ration and ANOVA. The results indicate that feed rate and cutting speed are the dominant parameters in turning of Ni-Hard with $62 \mathrm{HRC}$ and $50 \mathrm{HRC}$, respectively. Suresh et al. [17] studied the influence of cutting parameters on the surface roughness during hard turning of AISI 4340 high strength low alloy steel using coated carbide insert. It was found that better surface roughness could be achieved at higher cutting speed with lower feed rate and depth of cut. Philip and Chandramohan [18] investigated the surface roughness during dry turning of AISI 304 Austenitic Stainless Steel. They reported that feed rate has the most significant influence on surface roughness, followed by cutting speed and depth of cut. Ali Riza [19] performed an investigation on surface roughness in turning of AISI 8660 hardened alloy steels using PVD coated ceramic cutting tools under different conditions. The results indicated that the feed rate and depth of cut have the greatest effect on surface roughness. Bhattacharya et al. [20] conducted a study on the effect of cutting parameters on the surface roughness by high speed machining of AISI 45 steel. The result showed that the influence of cutting speed on surface roughness is significant, while the other parameters do not have substantial effect on the surface roughness. An investigation performed by Dilbag and Venkateswara [21] on finish hard turning of the bearing steel (AISI 52100) with Mixed ceramic inserts made up of aluminum oxide and titanium carbonitride (SNGA) showed that the feed rate has the greatest effect on surface roughness followed by cutting speed and tool rake.

Thus the purpose of this work is to investigate the influence of tool construction, tool overhang and cutting parameters (spindle speed, depth of cut and feed rate) on the surface roughness $\left(R_{a}\right)$ and vibration in turning of AISI1045 steel. Two forms of cutting tools made of AISI 5140 steel were used: the standard cutting tool and cutting tool with a new design of toolholder, which has horizontal holes arranged in a chess-board pattern (Figure 1). The experiments were performed under dry conditions. Three levels for spindle speed $(n)$, feed rate $(f)$, depth of cut $(a)$ and tool overhang $(l)$ were selected. The influence of the cutting parameters on the surface roughness and natural frequency was tested by using Taguchi method. $\mathrm{L}_{9}$ orthogonal array was used in the design of experiment. Therefore, 9 trials were planned for each cutting tool. The cutting parameters and their levels are illustrated in Table 1.

\section{Materials and Method}

\subsection{Design of Experiment}

In any business finding appropriate method to improve quality and increase productivity plays an important role. The conventional methods based on trial-and-error searches are complex, time-consuming and costly; hence they are changed to the powerful and cost effective statistical methods [16]. Design of experiment is one of the

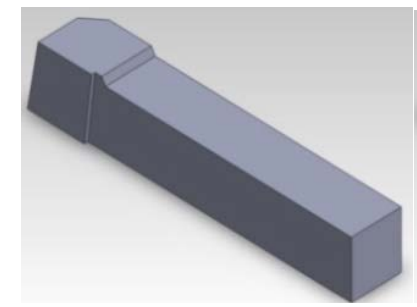

(a)

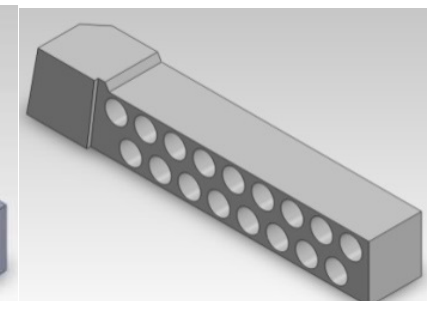

(b)
Figure 1. 3D-model of the cutting tools inSolidWorks: a) standard cutting tool; b) cutting tool with horizontal holes arranged in a chess-board pattern $(\varnothing 10 \mathrm{~mm})$.

Table 1. Cutting parameters and their levels.

\begin{tabular}{cccc}
\hline Variables & Level 1 & Level 2 & Level 3 \\
\hline A-Spindle speed (rpm) & 630 & 800 & 1000 \\
B-Feed rate (mm/rev) & 0.05 & 0.06 & 0.075 \\
C-Depth of cut (mm) & 0.05 & 0.1 & 0.15 \\
D-Overhang (mm) & 41 & 50 & 65 \\
\hline
\end{tabular}


widely used methods, which is centered on factors, responses, and runs in the experiment process. It is used as an important tool in the engineering design activities and for improving the performance of a manufacturing process. Design of experiments is able to determine unknown factors and the influence of the factors on the response [18].

Taguchi method is one of the important tools used in the industry to shortage product design, develop time and produce lower product cost. Taguchi method also takes into consideration the effect of uncontrollable factors on the response. This method is also highly flexible and can allocate different levels of factors, even when the numbers of the levels of factors are not the same [16]. In Taguchi approach, optimization, data analysis and the prediction of the optimum results are provided by objective function, which is called signal to noise ratio $(\mathrm{S} / \mathrm{N})$. Signal factors represent system control inputs. Noise factors represent variables, which are expensive or difficult to control. The S/N ratios generally used are: the-nominalthe better, the-lower-the-better and the-larger-the-better. Different parameters affect the response to a different degree. Using analysis of variance (ANOVA) the relative effect of the different parameters is determined. $\mathrm{S} / \mathrm{N}$ ratio and ANOVA provide determining of the optimum cutting parameters for the response [22]. Finally, confirmation testsare recommended in Taguchi method to verify the effectiveness and efficiency of the Taguchi method in optimizing the parameters.

In this investigation, cutting parameters are optimized for the average surface roughness $\left(R_{a}\right)$ and natural frequency in turning of AISI 1045 steel. The responses variables are measured in micrometer $(\mu \mathrm{m})$ and hertz $(\mathrm{Hz})$, correspondently. Three levels of spindle speed $(n)$, feed rate $(f)$, depth of cut $(a)$ and tool overhang $(l)$ and two different cutting tools are utilized as cutting parameters. In the design of experiment the $\mathrm{L}_{9}$ orthogonal array of Taguchi method was used.

Optimization of the cutting parameters for both cutting tools has been performed separately. For surface roughness and natural frequency analysis the-smaller-the-better performance characteristics were used. Therefore, in this case $\mathrm{S} / \mathrm{N}$ ratio $(\eta)$ is defined as:

$$
\eta=-10 \log \left(\frac{1}{n} \sum_{i=1}^{n} Y_{i}^{2}\right)
$$

where $\eta$ is the $\mathrm{S} / \mathrm{N}$ ratio, $\mathrm{n}$ is the number of experiment and $Y_{i}$ is the observed data. Using Equation (1) the $\mathrm{S} / \mathrm{N}$ ratios of the variable parameters are calculated for the average surface roughness and natural frequency.

In ANOVA, the 95\% confidence level was chosen to determine the factors effect on the average surface roughness and natural frequency. The optimization processes were performed by using the powerful statistical analysis software Minitab 16, which is used to improve the quality in different fields, such as: statistics, sports, mathematics, economics and engineering.

\subsection{Experimental Procedure}

Machining experiments were carried out at the lathe machine model 16K20VF1 (Russia), which has a maximum spindle speed of $1600 \mathrm{rpm}$ and maximum power of 5.5 $\mathrm{kW}$. The standard cutting tool and a new model of cutting tool with horizontal holes in toolholder arranged in a chess-board pattern, with general specification of PCLNR 2525M12 made of AISI 5140, were used (Figure 1). Carbide rhombic cutting insert with a general specification of CT35M coated with TiC, manufactured by Sandvik Coromant, was used as a cutting tool insert. In this study AISI1045 steel was used as workpiece with $65 \mathrm{~mm}$ diameter and $200 \mathrm{~mm}$ length. The chemical compositions of the selected material by weight percentage are shown in Table 2. During turning the homogeneity of the workpiece material affects the experimental result, so to reduce its effect on the results, in each trial the rust layers were removed by using a new cutting insert. Also, in each trial a new cutting insert CT35M coated with TiC was used in order to minimize the effect of tool wear on the experimental results.

In this study, the average surface roughness $\left(R_{a}\right)$, which is one of the most important criteria in machining process, is selected. Measurement of the average surface roughness $\left(R_{a}\right)$ was performed using a profile meter model 130 (Russia) with a sampling length of $12.50 \mathrm{~mm}$ and measurement speed of $0.5 \mathrm{~mm} / \mathrm{s}$. The values of the average surface roughness $\left(R_{a}\right)$ were calculated by averaging four roughness values obtained from four different points of machined surface in $90^{\circ}$ increments around the circumference. Frequencies occurred during machining was measured using piezoelectric accelerometer KD-35 and ZETLAB software (Russia). For this purpose on the lower side of the cutting edge of the tools the piezoelectric accelerometerKD-35 was attached. Vibrations occurred during machining were recorded by KD-35 and passed through the multifunctional spectrum analyzer A17-U8 to a personal computer to visualize the results.

\section{Experimental Results and Discussion}

\subsection{Evaluation of Surface Roughness for AISI 1045 Steel}

The experiments were performed according to the $\mathrm{L}_{9}$

Table 2. Chemical compositions of AISI 1045 steel.

\begin{tabular}{cccccc}
\hline Element & Fe & Mn & C & S & P \\
\hline Weight (\%) & 98.51 & 0.9 & 0.5 & 0.05 & 0.04 \\
\hline
\end{tabular}


orthogonal array. The average surface roughness $\left(R_{a}\right)$ during machining of AISI 1045 steel was measured and then according to the Taguchi's "the-smaller-the-better" quality characteristics the $\mathrm{S} / \mathrm{N}$ ratios were calculated. The experimental results of $R_{a}$ and $\mathrm{S} / \mathrm{N}$ ratios are given in Table 3.

Figures 2-4 illustrate the relationships between $R_{a}$ and cutting parameters in turning of AISI 1045 steel for both cutting tools. As it can be seen from graphs 2 to 4, however the $R_{a}$ values show irregular tendencies, they show similar trends for both cutting tools. The irregular tendency of surface roughness values can be explained by randomized distribution of cutting parameters due to design of experiment. In Figures 2(a) and 2(b) it can be clearly seen, that surface roughness decreased with increasing spindle speed for both cutting tools at $0.05 \mathrm{~mm} /$ rev feed rate. At $0.06 \mathrm{~mm} / \mathrm{rev}$ feed rate for cutting tool with holes in toolholder, the smallest value of $R_{a}$ was observed due to $1000 \mathrm{rpm}$ spindle speed. The highest value of the $R_{a}$ has been obtained as $2.673 \mu \mathrm{m}$ in turning of AISI 1045 steel with cutting tool with holes in toolholder at $0.075 \mathrm{~mm} / \mathrm{rev}$ feed rate and $630 \mathrm{rpm}$ spindle speed (Table 3).

Figure 3 indicates that $R_{a}$ value decreases as spindle speed and depth of cut increase from $630 \mathrm{rpm}$ to 1000 rpm and $0.05 \mathrm{~mm}$ to $0.15 \mathrm{~mm}$, respectively, except increase in depth of cut at $630 \mathrm{rpm}$ and $1000 \mathrm{rpm}$ spindle speed for cutting tool with holes in toolholder. Besides, it was determined that the $R_{a}$ values obtained by standard cutting tool at all cutting conditions, except $630 \mathrm{rpm}$ spindle speed are higher. At $0.15 \mathrm{~mm}$ depth of cut and $630 \mathrm{rpm}$ spindle speed the highest $R_{a}$ value was obtained for cutting tool with holes in toolholder (Table 3 ).

As seen from Figure 4, when the $R_{a}$ values for $50 \mathrm{~mm}$ tool overhang were evaluated, the $R_{a}$ values obtained by

Table 3. Experimental results and $\mathrm{S} / \mathrm{N}$ ratios for $\boldsymbol{R}_{\boldsymbol{a}}$.

\begin{tabular}{ccccccccc}
\hline $\begin{array}{c}\text { Exp. } \\
\text { No. }\end{array}$ & $\mathrm{A}$ & $\mathrm{B}$ & $\mathrm{C}$ & $\mathrm{D}$ & $R_{a 1},(\mu \mathrm{m})$ & $\begin{array}{c}\mathrm{S} / \mathrm{N} \text { ratio } \\
(\mathrm{dB})\end{array}$ & $R_{a 2},(\mu \mathrm{m})$ & $\begin{array}{c}\mathrm{S} / \mathrm{N} \text { ratio } \\
(\mathrm{dB})\end{array}$ \\
\hline 1 & 1 & 1 & 1 & 1 & 2.0720 & -6.32780 & 2.390 & -7.56796 \\
2 & 1 & 2 & 2 & 2 & 2.4900 & -7.92399 & 1.920 & -5.66602 \\
3 & 1 & 3 & 3 & 3 & 1.8310 & -5.25377 & 2.673 & -8.53998 \\
4 & 2 & 1 & 2 & 3 & 1.3840 & -2.82272 & 0.974 & 0.22882 \\
5 & 2 & 2 & 3 & 1 & 1.0810 & -0.67651 & 0.859 & 1.32014 \\
6 & 2 & 3 & 1 & 2 & 1.2190 & -1.72007 & 1.200 & -1.58362 \\
7 & 3 & 1 & 3 & 2 & 1.0330 & -0.28201 & 0.588 & 4.61245 \\
8 & 3 & 2 & 1 & 3 & 1.3200 & -2.41148 & 0.569 & 4.89775 \\
9 & 3 & 3 & 2 & 1 & 1.3971 & -2.90455 & 1.640 & -4.29668 \\
\hline
\end{tabular}

$R_{a 1}$ —surface roughness value for standard cutting tool and $R_{a 2}$ —surface roughness value for cutting tool with holes.

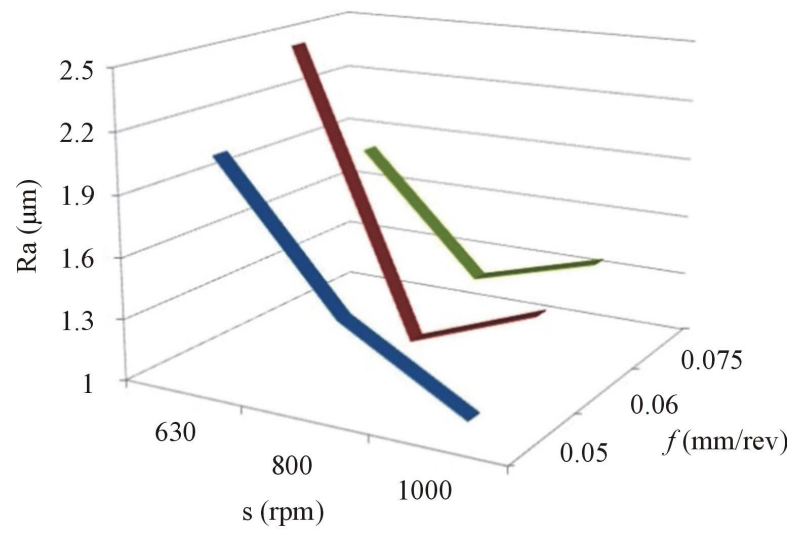

(a)

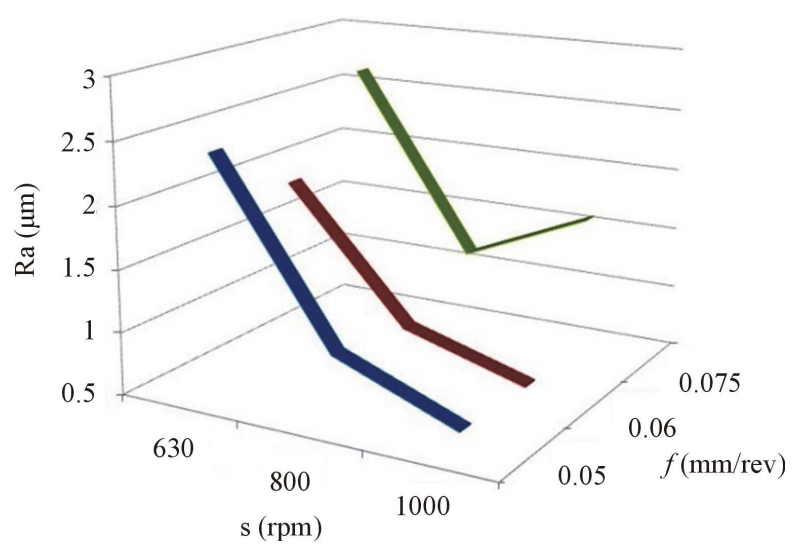

(b)

Figure 2. Relationship between $\boldsymbol{R}_{a}$, spindle speed (s) and feed rate (f) in turning of AISI 1045 steel: (a) with standard cutting tool and (b) with cutting tool with holes in toolholder.

cutting tool with holes in toolholder decreased parallel to increase in the spindle speed while the $R_{a}$ values obtained by standard cutting tool showed an irregular tendency. On the other hand, the $R_{a}$ values for both cutting tools showed similar trends at $41 \mathrm{~mm}$ and $65 \mathrm{~mm}$ tool overhangs. The $R_{a}$ value decreases as tool overhang increases, except $800 \mathrm{rpm}$ spindle speed for standard cutting tool. While, increase in tool overhang, except $1000 \mathrm{rpm}$ spindle speed, increases the $R_{a}$ value for cutting tool with holes in toolholder. The highest and smallest $R_{a}$ values were obtained at $630 \mathrm{rpm}$ and $1000 \mathrm{rpm}$ spindle speed, correspondently, at $65 \mathrm{~mm}$ tool overhang with cutting tool with holes in toolholder (Table 3 ). The results show that the need to choose higher spindle speed is revealed to achieve the small $R_{a}$ value during machining of AISI 1045 steel with both cutting tools.

According to the Equation (1) the $\mathrm{S} / \mathrm{N}$ ratios of average surface roughness obtained from experimental results were calculated, which are used to identify the optimal levels of each factor (Table 3 ).

The graphs of $\mathrm{S} / \mathrm{N}$ ratios of $R_{a}$ for both cutting tools are illustrated in Figure 5. The power of the factor effect 


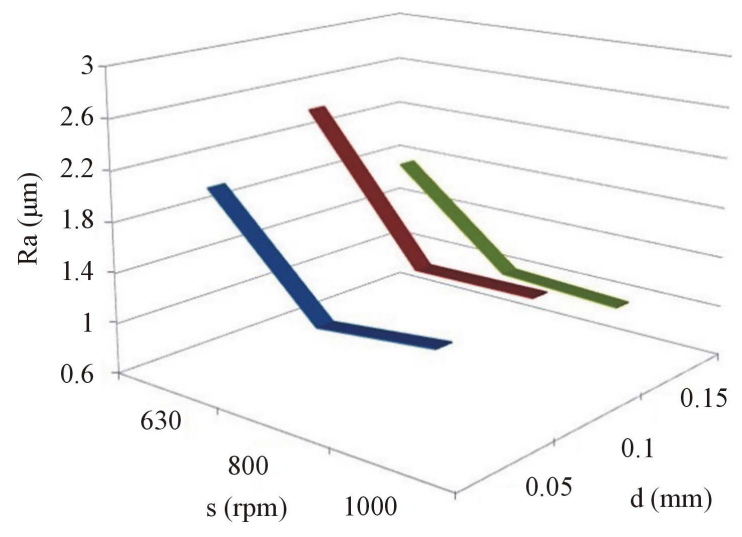

(a)

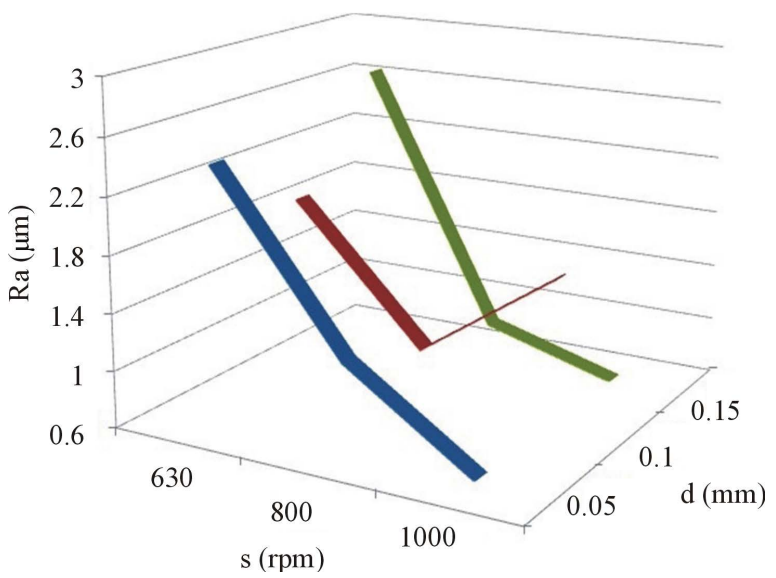

(b)

Figure 3. Relationship between $R_{a}$, spindle speed (s) and depth of cut (d) in turning of AISI 1045 steel: (a) with standard cutting tool and (b) with cutting tool with holes in toolholder.

on the $R_{a}$ is determined by the slope of the line. The graphs reveal a dominant effect of spindle speed on the surface roughness. The significant influence of spindle speed can be explained by the fact that as spindle speed increases, the interaction between cutting tool and workpiece decreases, which leads to less vibration and consequently to better surface roughness. From the Figure 5 and Table 3, one can observe that the optimal combination of cutting parameter levels in turning of AISI 1045 steel is $A_{2} B_{1} C_{3} D_{1}$ for standard cutting tool and $A_{3} B_{2} C_{3} D_{2}$ for cutting tool with holes in toolholder. The smallest values of $\mathrm{S} / \mathrm{N}$ ratio and surface roughness under optimum conditions are predicted using Equations (2) and (3) [23].

$$
\begin{gathered}
\eta_{\text {opt }}=m+\sum\left(m_{i}-m\right) \\
R a_{\text {opt }}=10^{-\frac{\eta_{\text {opt }}}{20}}
\end{gathered}
$$

where: $\eta_{\text {opt }}$ is the $\mathrm{S} / \mathrm{N}$ ratio under optimum conditions (dB), $m$ is the overall mean value of $\mathrm{S} / \mathrm{N}$ ratio for the experimental region $(\mathrm{dB}), m_{i}$ is the $\mathrm{S} / \mathrm{N}$ ratio when the

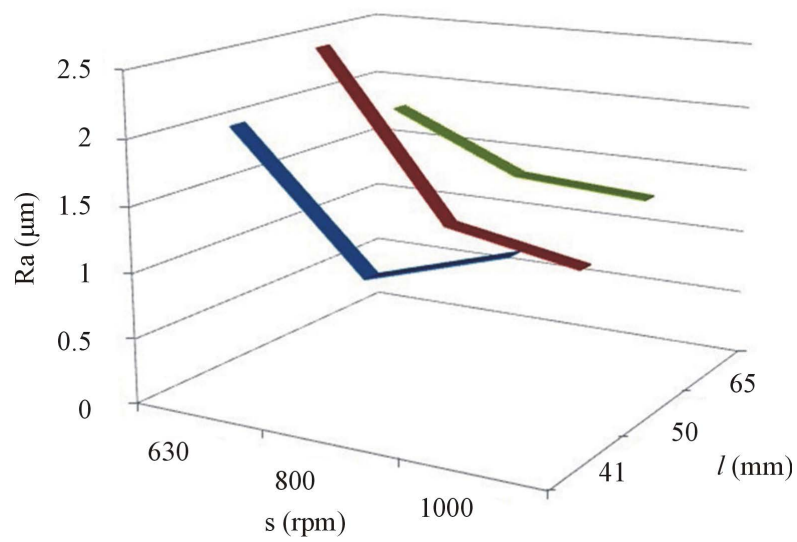

(a)

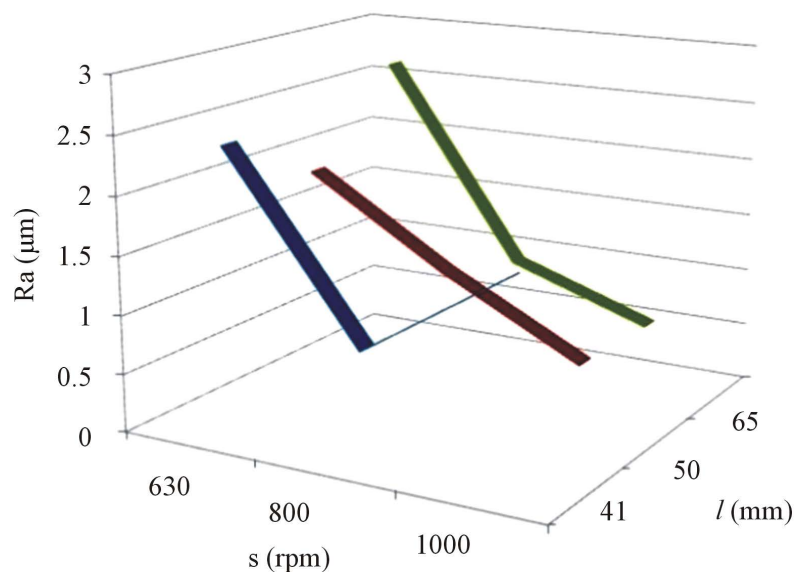

(b)

Figure 4. Relationship between $R_{a}$, spindle speed (s) and tool overhang (l) in turning of AISI 1045 steel: (a) with standard cutting tool and (b) with cutting tool with holes in toolholder.

variable parameter is at optimum level (dB) and $R a_{\text {opt }}$ is the surface roughness under optimum condition.

Predicted $\mathrm{S} / \mathrm{N}$ ratios and surface roughness values were determined as $-0.150028 \mathrm{~dB}$ and $1.017 \mu \mathrm{m}$, respectively, for standard cutting tool and $5.7053 \mathrm{~dB}$ and $0.518 \mu \mathrm{m}$, correspondently, for cutting tool with holes in toolholder.

However, the statistical analysis ANOVA was conducted to find the relative contribution of each cutting parameter on the $R_{a}$ and confirm initial assumption of the optimal conditions. The ANOVA results for $\mathrm{S} / \mathrm{N}$ ratio are illustrated in Tables 4 and 5. Here, $P$ value indicates the influence of the factor on the $R_{a}$ as: significant if $\mathrm{P}<0.05$; mildly significant if $0.05<\mathrm{P}<0.1$ and insignificant if $\mathrm{P}>$ 0.1 . Taking into consideration the F-ratio, the significance of the factor effect is determined. The ratio of factor mean square to the error mean square is called Fisher's ratio $(F)$. It is used to determine whether the parameter has a significant effect on the quality characteristic by comparing the $F$ test value of the parameter with the standard $F$ table value $\left(F_{\alpha}\right)$ at the $\alpha$ significance level. 


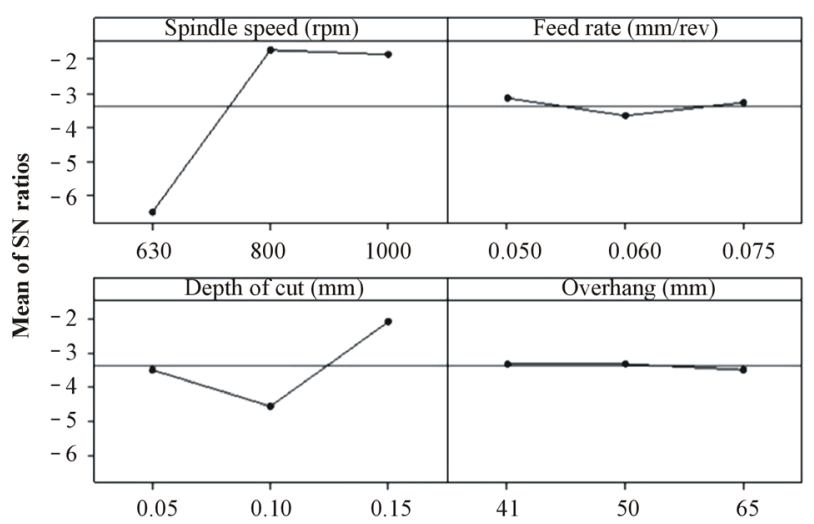

(a)

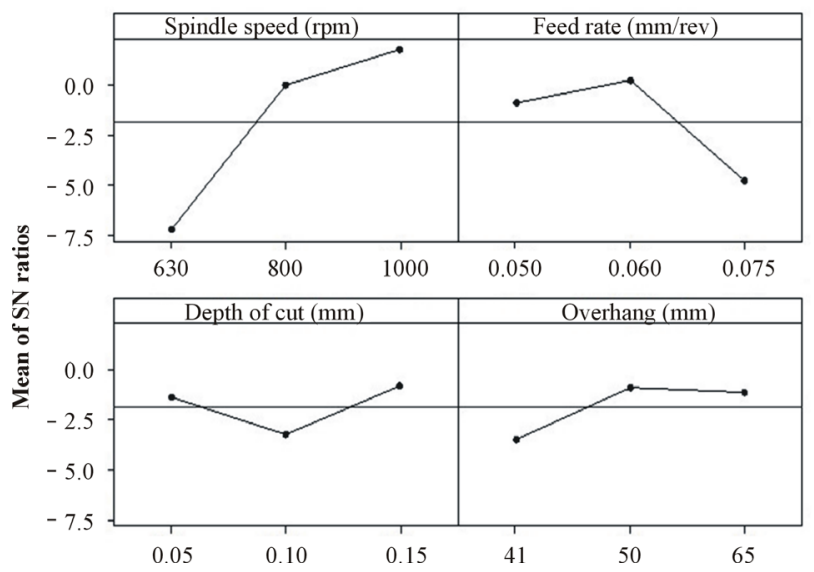

(b)

Figure 5. Maine effect plots for $\mathrm{S} / \mathrm{N}$ ratios of $\boldsymbol{R}_{a}$ for: (a) standard cutting tool and (b) cutting tool with holes in toolholder.

Table 4. ANOVA for $\boldsymbol{R}_{\boldsymbol{a}}$ of AISI 1045 with standard cutting tool.

\begin{tabular}{ccccccc}
\hline Source & DF & SS & MS & $F$ ratio & P value & \% of Total \\
\hline A & 2 & 1.59200 & 0.796000 & 64.58410 & 0.025 & 82.31 \\
B & 2 & $0.04005^{*}$ & 0.007950 & 0.64503 & 0.780 & 2.07 \\
C & 2 & 0.29309 & 0.036965 & 2.99918 & 0.719 & 15.15 \\
D & 2 & $0.00888^{*}$ & 0.000190 & 0.16227 & 0.989 & 0.46 \\
Error & 0 & 0 & 0 & & & \\
Total & 8 & 1.93402 & & & & 100 \\
(error) & $(4)$ & 0.04893 & 0.012325 & & & \\
\hline & & \multicolumn{5}{c}{}
\end{tabular}

The analysis was performed for a confidence level of $95 \% . F_{0.05}$ for parameters degree of freedom $\left(\mathrm{df}_{1}=2\right)$ and error degree of freedom $\left(\mathrm{df}_{2}=4\right)$ is 6.9443 . To be significant the calculated $F$-ratio for each design parameter must be greater than $F_{0.05}$ as shown in the ANOVA table. The ANOVA results indicate that the $R_{a}$ of AISI 1045 is significantly influenced by spindle speed with $82.31 \%$ and $77 \%$ for standard cutting tool and cutting tool with
Table 5. ANOVA for $\boldsymbol{R}_{a}$ of AISI 1045 with cutting tool with holes in toolholder.

\begin{tabular}{ccccccc}
\hline Source & DF & SS & MS & $F$ ratio & P value & \% of Total \\
\hline A & 2 & 3.68675 & 1.8433 & 24.4302 & 0.025 & 77.00 \\
B & 2 & 0.83208 & 0.4160 & 6.19084 & 0.780 & 17.38 \\
C & 2 & $0.03484^{*}$ & 0.0174 & 0.25921 & 0.719 & 0.73 \\
D & 2 & $0.23397^{*}$ & 0.1169 & 1.74857 & 0.989 & 4.88 \\
Error & 0 & 0 & 0 & & & \\
Total & 8 & 4.78765 & & & & \\
(error) & $(4)$ & 0.26881 & 0.0672 & & & 100 \\
\hline
\end{tabular}

"Indicates sum of squares added together to estimate the pooled error sum of squares shown within parenthesis; DF-Degree of Freedom; SS-Sum of Squares; MS-Mean of Squares; A-Spindle speed; B-Feed rate; CDepth of Cut and D-Tool Overhang.

holes, respectively. Other factors that influence the $R_{a}$ are depth of cut with $15.15 \%$ for standard cutting tool, and feed rate with $17.38 \%$ for cutting tool with holes.

\subsection{Evaluation of Natural Frequency Occurred during Machining of AISI 1045 Steel}

In order to improve the design and implementation of new cutting tool, the effect of cutting conditions on vibration have to be established. In each trial, the natural frequency $(f)$ was recorded with the help of ZETLAB software and piezoelectric accelerometer KD-35. Cutting parameters and their level are illustrated in Table 1. According to the Taguchi's "the-smaller-the-better" quality characteristics the $\mathrm{S} / \mathrm{N}$ ratios were calculated. The experimental results for natural frequency and $\mathrm{S} / \mathrm{N}$ ratios are given in Table 6. Figures 6-8 have been constructed to illustrate the variation of natural frequency depending on spindle speed (s)-feed rate $(f)$, spindle speed (s)-depth of cut $(d)$ and spindle speed (s)-tool overhang $(l)$. These graphs indicate that natural frequency values for both cutting tools show similar trend, although they show irregular tendencies, which is probably caused by randomized distribution of cutting parameters due to design of experiment.

Figure 6 illustrates that at $0.05 \mathrm{~mm} / \mathrm{rev}$ and $0.06 \mathrm{~mm} /$ rev feed rate, increase in spindle speed decreases natural frequency value. On the other hand, increase in spindle speed at $0.075 \mathrm{~mm} / \mathrm{rev}$ increases natural frequency value. The highest natural frequency value has been observed as $3527.8 \mathrm{~Hz}$ in turning of AISI 1045 steel at $800 \mathrm{rpm}$ spindle speed and $0.06 \mathrm{~mm} / \mathrm{rev}$ feed rate performed by cutting tool with holes in toolholder (Table 6).

It can be noticed from Figure 7 that natural frequency decreased with increasing spindle speed at $0.05 \mathrm{~mm}$ depth of cut for both cutting tool. The natural frequency values of neither cutting tool showed a regular tendency 
Table 6. Experimental results and $\mathrm{S} / \mathrm{N}$ ratios for natural frequency.

\begin{tabular}{ccccccccc}
\hline $\begin{array}{c}\text { Exp. } \\
\text { No. }\end{array}$ & A & B & C & D & $f_{1}(\mathrm{~Hz})$ & $\begin{array}{c}\text { S/N ratio } \\
(\mathrm{dB})\end{array}$ & $f_{2}(\mathrm{~Hz})$ & $\begin{array}{c}\text { S/N ratio } \\
(\mathrm{dB})\end{array}$ \\
\hline 1 & 1 & 1 & 1 & 1 & 2795.4 & -68.9289 & 3271.5 & -70.2949 \\
2 & 1 & 2 & 2 & 2 & 3161.6 & -69.9981 & 2844.2 & -69.0792 \\
3 & 1 & 3 & 3 & 3 & 2069.1 & -66.3156 & 2185.1 & -66.7894 \\
4 & 2 & 1 & 2 & 3 & 2111.8 & -66.4931 & 2124.0 & -66.5431 \\
5 & 2 & 2 & 3 & 1 & 3173.8 & -70.0316 & 3527.8 & -71.4291 \\
6 & 2 & 3 & 1 & 2 & 2856.4 & -69.1164 & 2905.3 & -69.2638 \\
7 & 3 & 1 & 3 & 2 & 2636.7 & -68.4212 & 2966.3 & -69.4443 \\
8 & 3 & 2 & 1 & 3 & 2075.2 & -66.3412 & 2136.2 & -66.5928 \\
9 & 3 & 3 & 2 & 1 & 3039.6 & -69.6563 & 3192.1 & -70.0815 \\
\hline
\end{tabular}

$f_{1}$-Natural frequency value for standard cutting tool and $f_{2}$-Natural frequency value for cutting tool with holes.

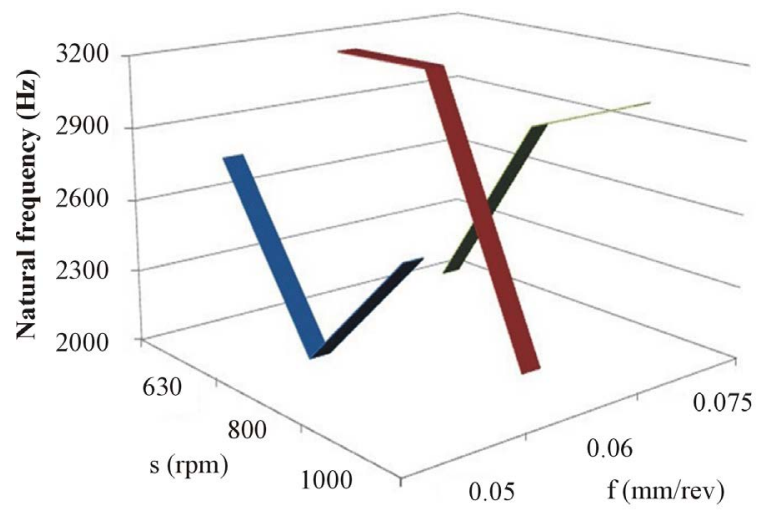

(a)

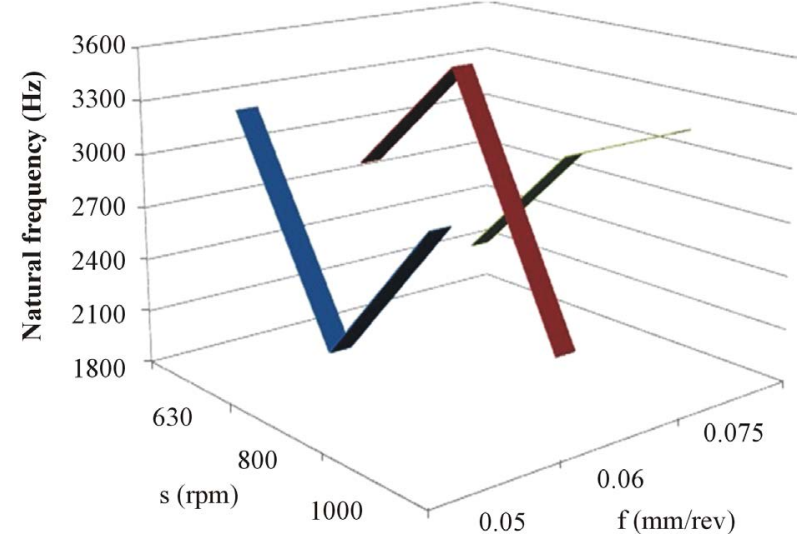

(b)

Figure 6. Relationship between natural frequency, spindle speed (s) and feed rate (f) AISI 1045 steel: (a) with standard cutting tool and (b) with cutting tool with holes in toolholder.

at $0.1 \mathrm{~mm}$ and $0.15 \mathrm{~mm}$ depth of cut. However, at 0.15 $\mathrm{mm}$ depth of cut the smallest and highest values of natural frequency were obtained due to $630 \mathrm{rpm}$ and $800 \mathrm{rpm}$

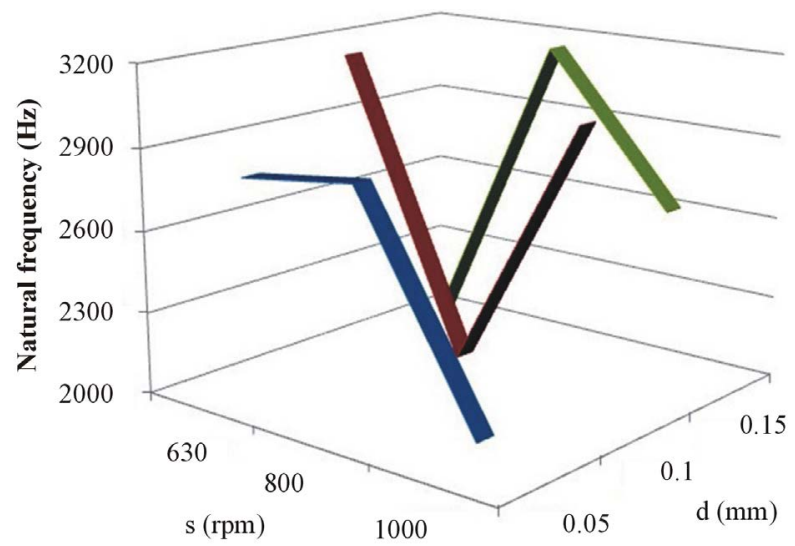

(a)

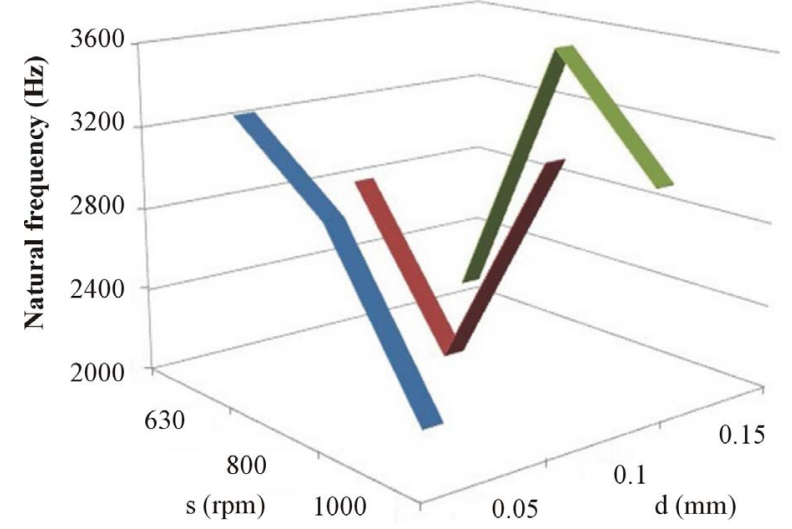

(b)

Figure 7. Relationship between natural frequency, spindle speed (s) and depth of cut (d) AISI 1045 steel: (a) with standard cutting tool and (b) with cutting tool with holes in toolholder.

for standard cutting tool and cutting tool with holes in toolholder, respectively (Table 6).

Figure 8 indicates that at $41 \mathrm{~mm}$ tool overhang the highest natural frequency value was obtained at $800 \mathrm{rpm}$ spindle speed, although the variation of natural frequency for both cutting tool was not regular. At $50 \mathrm{~mm}$ tool overhang the variation of spindle speed from $630 \mathrm{rpm}$ to $1000 \mathrm{rpm}$ has decreased and increased linearly the natural frequency for standard cutting tool and cutting tool with holes in toolholder, correspondently. During the experiment at which tool overhang is $65 \mathrm{~mm}$, natural frequency values increased parallel to spindle speed for standard cutting tool, while they have decreased for cutting tool with holes in toolholder, however, their values are close to each other. Additionally, for the same tool overhang the smallest value of natural frequency was determined as $2069.1 \mathrm{~Hz}$ due to $630 \mathrm{rpm}$ spindle speed (Table 6).

According to the Equation (1) the $\mathrm{S} / \mathrm{N}$ ratios of natural frequency obtained from experimental results were calculated, which are used to identify the optimal levels of 


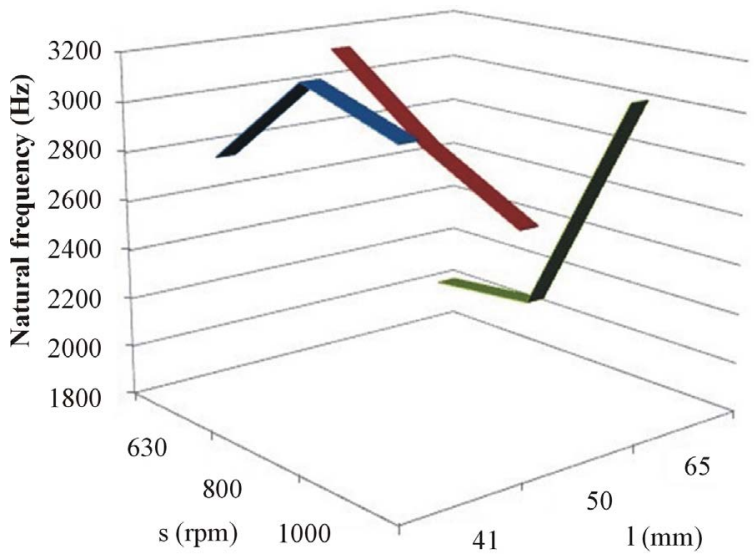

(a)

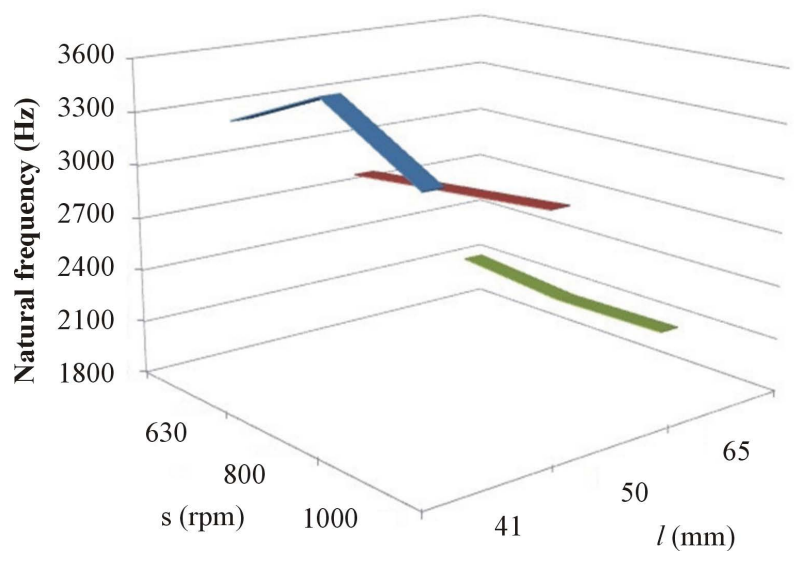

(b)

Figure 8. Relationship between natural frequency, spindle speed (s) and tool overhang (I) AISI 1045 steel: (a) with standard cutting tool and (b) with cutting tool with holes in toolholder.

each factor (Table 6). Figure 9 shows the graphs of $\mathrm{S} / \mathrm{N}$ ratios that were calculated for natural frequency of standard cutting tool and cutting tool with holes in toolholder in turning of AISI 1045 steel. The graphs reveal a significant effect of tool overhang on natural frequency. The influence of tool overhang can be explained by the fact that as tool overhang increases, stability of the tool decreases, which leads to more vibration of the tool and consequently to poor surface roughness. From the Figure 9 and Table 6, it can be revealed that the optimal combination of cutting parameter levels in turning of AISI 1045 steel is $A_{3} B_{1} C_{1} D_{3}$ for standard cutting tool and $A_{3} B_{3} C_{2} D_{3}$ for cutting tool with holes in toolholder. The smallest values of $\mathrm{S} / \mathrm{N}$ ratio and natural frequency under optimum conditions are predicted using Equations (2) and (3).

Predicted $\mathrm{S} / \mathrm{N}$ ratios and natural frequency values were determined as $-65.4968 \mathrm{~dB}$ and $1883.34 \mathrm{~Hz}$, respectively, for standard cutting tool and $-66.1215 \mathrm{~dB}$ and 2023.37 $\mathrm{Hz}$, correspondently, for cutting tool with holes in tool- holder.

The significance of the parameter on natural frequency occurred during turning of AISI 1045 steel with standard cutting tool and cutting tool with holes in toolholder was determined by ANOVA results given in Tables 7 and 8 . $F$-ratios and percent contribution of parameters in Tables 7 and 8 were taken into consideration to determine the significance of the factor effect. The ANOVA results show that tool overhang significantly affect natural frequency in turning of AISI 1045 steel with 87.496\% and

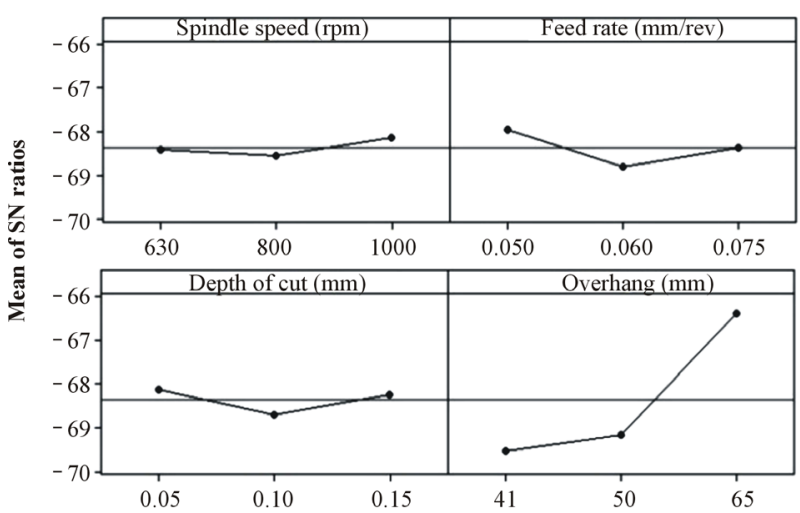

(a)

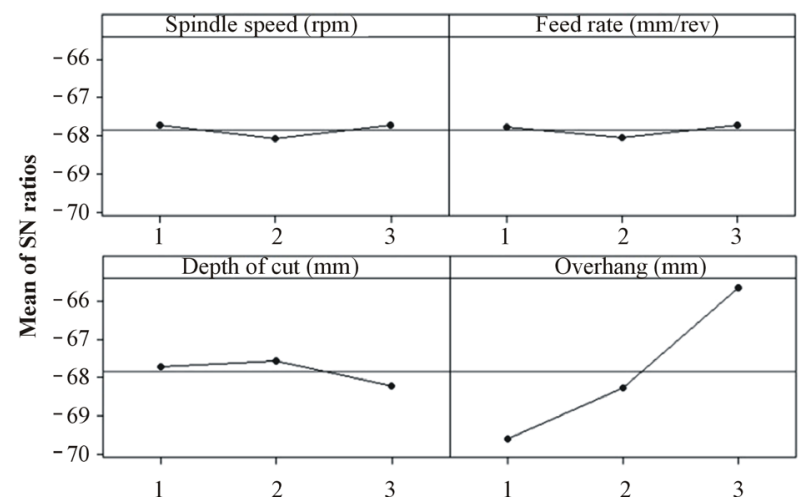

(b)

Figure 9. Maine effect plots for $\mathrm{S} / \mathrm{N}$ ratios of natural frequency for: (a) standard cutting tool and (b) cutting tool with holes in toolholder.

Table 7. ANOVA for natural frequency of AISI 1045 with standard cutting tool.

\begin{tabular}{ccccccc}
\hline Source & DF & SS & MS & $F$ ratio & P value & \% of Total \\
\hline A & 2 & $26,814^{*}$ & 13,407 & 0.6064 & 0.966 & 1.570 \\
B & 2 & 125,228 & 62,614 & 2.8323 & 0.875 & 7.330 \\
C & 2 & $61,613^{*}$ & 30,807 & 1.3935 & 0.506 & 3.604 \\
D & 2 & $1,495,114$ & 697499.5 & 31.5514 & 0.009 & 87.496 \\
Error & 0 & 0 & 0.00 & & & \\
Total & 8 & $1,708,769$ & & & & \\
(error) & $(4)$ & 88,427 & 22106.75 & & & 100 \\
\hline
\end{tabular}


93.072\% for standard cutting tool and cutting tool with holes, respectively. Other factors that influence the natural frequency are the feed rate with $7.3 \%$ and depth of cut with $3.749 \%$ for standard cutting tool and cutting tool with holes, respectively.

General evaluation is made in terms of cutting tool construction, the $R_{a}$ and natural frequency values in turning of AISI 1045 steel obtained by cutting tool with holes are less and greater than those of standard cutting tool, respectively. This can be explained by the fact that the cutting tool with holes has the heterogeneous structure. Vibration waves pass through the mediums: metalair-metal-air. Vibration suppression, their partial reflection and the change of direction occur because the holes are staggered in toolholder. As a result, vibrations are damped, which stabilizes the position of the tool leading to improve the surface quality. Therefore, it is possible to say that construction of cutting tool is an important factor for $R_{a}$ and natural frequency. According to ANOVA results, it was also found that spindle speed has the significant influence on $R_{a}$, while this variable is tool overhang

Table 8. ANOVA for natural frequency of AISI 1045 with cutting tool with holes.

\begin{tabular}{ccccccc}
\hline Source & DF & SS & MS & F ratio & P value & \% of Total \\
\hline A & 2 & $46,906^{*}$ & 23,453 & 1.148 & 0.963 & 1.840 \\
B & 2 & $34,167^{*}$ & 17,083 & 0.836 & 0.973 & 1.339 \\
C & 2 & 95,635 & 47,818 & 2.341 & 0.210 & 3.749 \\
D & 2 & $2,373,981$ & $1,186,991$ & 58.112 & 0.001 & 93.072 \\
Error & 0 & 0 & 0 & & & \\
Total & 8 & $2,550,689$ & 20425.75 & & & 100.00 \\
(error) & $(4)$ & 81,073 & & & & \\
\hline
\end{tabular}

*Indicates sum of squares added together to estimate the pooled error sum of squares shown within parenthesis; DF-Degree of Freedom; SS-Sum of Squares; MS-Mean of Squares; A-Spindle speed; B-Feed rate; CDepth of Cut and D-Tool Overhang. for natural frequency for both cutting tool.

\subsection{Confirmation Experiments}

When the optimal combination of cutting parameters does not correspond to any trial runs already completed in the orthogonal array, the verification of the predicted result is recommended by Taguchi using confirmation tests at the chosen setting. The confirmation tests results performed at the optimum variable levels were evaluated by taking into consideration the confidence interval (CI) at $95 \%$ confidence band to statistically judge the closeness of the predicted and experimental results. The CI is calculated from Equations (4) and (5) [23].

$$
\begin{gathered}
C I=\sqrt{F_{0.05}\left(1, f_{e}\right) V_{e}\left(\frac{1}{n_{e f f}}+\frac{1}{r}\right)} \\
n_{\text {eff }}=\frac{N}{1+v}
\end{gathered}
$$

where $F_{0.05}\left(1, f_{e}\right)$ is the $F$ value from statistic table at $95 \%$ confidence level, $f_{e}$ is the error degree of freedom, $V_{e}$ is the mean square of error, $n_{\text {eff }}$ is the repeating number of the experiments, $r$ is the number of confirmation experiments, $N$ is the total number of the experiments and $v$ is total degree of freedom of all variables.

Tables 9 and 10 show the comparison of the results of the confirmation tests between experimental values conducted according to the optimum levels of the parameters and predicted values using Equations (2) and (3) for surface roughness $\left(R_{a}\right)$ and natural frequency $(f)$ for both cutting tools. The optimal levels of variables are valid if the difference between predicted $\mathrm{S} / \mathrm{N}$ ratio and $\mathrm{S} / \mathrm{N}$ ratio obtained experimentally is within CI value.

At the 95\% confidence level, the CIs of $R_{a}$ were calculated according to the Equations (4) and (5), which are $\pm 0.436 \mathrm{~dB}$ and $\pm 1.018 \mathrm{~dB}$ for standard cutting tool and cutting tool with holes in toolholder, respectively. Simi-

\begin{tabular}{|c|c|c|c|c|c|c|}
\hline \multirow[t]{2}{*}{ Type of cutting tool } & \multicolumn{2}{|c|}{ Experimental results } & \multicolumn{2}{|c|}{ Predicted results } & \multicolumn{2}{|c|}{ Differences } \\
\hline & $R a_{\text {exp }}, \mu \mathrm{m}$ & $\eta_{\text {exp }}, \mathrm{dB}$ & $R a_{\text {pred }}, \mu \mathrm{m}$ & $\eta_{\text {pred }}, \mathrm{dB}$ & $R a_{\text {exp }}-R a_{\text {pred }}$ & $\eta_{\text {exp }}-\eta_{\text {pred }}$ \\
\hline Cutting tool with holes & 0.56 & 5.0362 & 0.518 & 5.7053 & 0.042 & 0.6691 \\
\hline
\end{tabular}

Table 9. Comparison between experimental and predicted results of surface roughness.

\begin{tabular}{|c|c|c|c|c|c|c|}
\hline \multirow[t]{2}{*}{ Type of cutting tool } & \multicolumn{2}{|c|}{ Experimental results } & \multicolumn{2}{|c|}{ Predicted results } & \multicolumn{2}{|c|}{ Differences } \\
\hline & $f_{\text {exp }}, \mathrm{Hz}$ & $\eta_{\exp }, \mathrm{dB}$ & $f_{\text {pred }}, \mathrm{Hz}$ & $\eta_{\text {pred }}, \mathrm{dB}$ & $f_{\text {exp }}-f_{\text {pred }}$ & $\eta_{\text {exp }}-\eta_{\text {pred }}$ \\
\hline Cutting tool with holes & 2087.4 & -66.392 & 2023.37 & -66.1215 & 64.03 & -0.2705 \\
\hline
\end{tabular}

Table 10. Comparison between experimental and predicted results of natural frequency. 
larly, the CIs of natural frequency are $\pm 583.80 \mathrm{~dB}$ and \pm $561.16 \mathrm{~dB}$ for standard cutting tool and cutting tool with holes in toolholder, correspondently. It can be seen from Tables 9 and 10 that the difference between $R_{a}$ values and difference between natural frequencies values for both cutting tools are within CI values. Hence, the optimal levels of variables can be validated.

\section{Conclusions}

In this study, with the help of $\mathrm{S} / \mathrm{N}$ ratio and ANOVA results, the effects of cutting parameters and cutting tool construction on average surface roughness and natural frequency in turning of AISI 1045 steel under dry condition were evaluated to determine the optimum cutting conditions. Turning operations were performed by using standard cutting tool and cutting tool with holes in toolholder made of AISI 5140. The experimental results revealed that:

- The obtained results confirm one more time the successful implementation of Taguchi method in machining researches.

- The smallest $R_{a}$ values occurring in turning of AISI 1045 steel are $1.033 \mu \mathrm{m}$ and $0.569 \mu \mathrm{m}$ for standard cutting tool and cutting tool with holes in toolholder, respectively.

- The smallest natural frequency values occurring in turning of AISI 1045 steel are $2069.1 \mathrm{~Hz}$ and 2124 $\mathrm{Hz}$ for standard cutting tool and cutting tool with holes in toolholder, correspondently.

- Using ANOVA, the most significant parameter was determined, which was spindle speed for $R_{a}$, while this variable was tool overhang for natural frequency for both cutting tools.

\section{Acknowledgements}

This research was supported by People’s Friendship University of Russia in 2013.

\section{REFERENCES}

[1] C. Thomas, M. Katsuhiro, O. Toshiyuki and Y. Yasuo, "Metal Cutting," Great Britain, 2000.

[2] J. Serge, "Metal Cutting Mechanics and Material Behavior,” Technischeuniversitiet Eindhoven, 1999.

[3] K. K. Rama and J. Srinivas, "Study of Tool Dynamics with a Discrete Model of Workpiece in Orthogonal Turning," International Journal of Machining and Machinability of Materials, Vol. 10, No. 1-2, 2011, pp. 71-85.

[4] A. A. Tareq, "Extending the Technological Capability of Turning Operation,” International Journal of Engineering, Science and Technology, Vol. 2, No. 1, 2009, pp. 192201.

[5] K. A. Samir Mahammod Hassan and G. Amro, "Investigation into the Turning Parameters Effect on the Surface
Roughness of Flame Hardened Medium Carbon Steel with TiN- $\mathrm{Al}_{2} \mathrm{O}_{3}$-TiCN Coated Inserts Based on Taguchi Technique," World Academy of Science, Engineering and Technology, Vol. 59, 2011, pp. 2137-2141.

[6] M. Dogra, V. S. Sharma and J. Dureja, "Effect of Tool Geometry Variation on Finish Turning-A Review," Jour-nal of Engineering Science and Technology Review, Vol. 4, No. 1, 2011, pp. 1-13.

[7] L. V. Martinez, J. C. Jauregui-Correa and E. Rubio-Cerda, "Analysis of Compliance between the Cutting Tool and the Workpiece on the Stability of a Turning Process," International Journal of Machine Tools and Manufacture, Vol. 48, No. 9, 2008, pp. 1054-1062.

http://dx.doi.org/10.1016/j.ijmachtools.2007.10.016

[8] K. Yusuke, M. S. Doruk, A. Yusuf, S. Norikzau and S. Eiji, "Chatter Stability in Turning and Milling with In Process Identified Process Damping," Journal of Advanced Mechanical Design, Systems and Manufacturing, Vol. 4, No. 6, 2010, pp. 1107-1118. http://dx.doi.org/10.1299/jamdsm.4.1107

[9] K. Ramesh and T. Alwarsamy, "Investigation of Modal Analysis in the Stability of Boring Tool Using Double Impact Dampers Model Development,” European Journal of Scientific Research, Vol. 80, No. 2, 2012, pp. 182190.

[10] R. Mahdavinejad, "Finite Element Analysis of Machine and Workpiece Instability in Turning," International Journal of Machine Tools and Manufacture, Vol. 45, No. 7-8, 2005, pp. 753-760. http://dx.doi.org/10.1016/j.ijmachtools.2004.11.017

[11] S. Kanase and V. Jadhav, "Enhancement of Surface Finish of Boring Operation Using Passive Damper," Indian Journal of Applied Research, Vol. 2, No. 3, 2012, pp. 68-70.

[12] S. S. Abuthakeer, P. V. Mohanram and G. Mohan Kumar, "Prediction and Control of Cutting Tool Vibration Cnc Lathe with Anova and Ann,” International Journal of Lean Thinking, Vol. 2, No. 1, 2011, pp. 1-23.

[13] L. N. Devin and A. A. Osaghchii, "Improving Performance of cBN Cutting Tools by Increasing their Damping Properties,” Journal of Superhard Materials, Vol. 34, No. 5, 2012, pp. 326-335. http://dx.doi.org/10.3103/S1063457612050073

[14] M. Sortino, G. Totis and F. Prosperi, "Development of a Practical Model for Selection of Stable Tooling System Configurations in Internal Turning," International Journal of Machine Tools \& Manufacture, Vol. 61, 2012, pp. 58-70.

http://dx.doi.org/10.1016/j.ijmachtools.2012.05.010

[15] J. Kopač, A. Stoić and M. Lucić, "Experimental Investigation of Dynamic Instability of the Turning Process," Computational Materials Science and Surface Engineering, Vol. 1, No. 2, 2009, pp. 84-91.

[16] G. Mustafa and Y. Emre, "Application of Taguchi Method for Determining Optimum Surface Roughness in Turning of High-Alloy White Cast Iron,” Measurement, Vol. 46, No. 2, 2013, pp. 913-919. http://dx.doi.org/10.1016/j.measurement.2012.10.013

[17] R. Suresh, S. Basavarajappa, V. N. Gaitonde and G. L. 
Samuel, "Machinability Investigations on Hardened AISI 4340 Steel Using Coated Carbide Insert,” International Journal of Refractory Metals and Hard Materials, Vol. 33, 2012, pp. 75-86.

http://dx.doi.org/10.1016/j.ijrmhm.2012.02.019

[18] D. S. Philip and P. Chandramohan, "Optimization of Surface Roughness of AISI 304 Austenitic Stainless Steel in Dry Turning Operation using Taguchi Design Method," Journal of Engineering Science and Technology, Vol. 5, No. 3, 2010, pp. 293-301.

[19] M. Ali Riza, "The Optimization of Machining Parameters Using the Taguchi Method for Surface Roughness of AISI 8660 Hardened Alloy Steel," Journal of Mechanical Engineering, Vol. 56, No. 6, 2010, pp. 391-401.

[20] A. Bhattacharya, S. Das, P. Majumder and A. Batish, "Estimating the Effect of Cutting Parameters on Surface
Finish and Power Consumption during High Speed Machining of AISI 1045 Steel Using Taguchi Design and ANOVA,” Journal of Research and Development, Vol. 3, 2009, pp. 31-40.

[21] S. Dilbag and P. R. Venkateswara, "A Surface Roughness Prediction Model for Hard Turning Process," International Journal of Advanced Manufacturing Technology, Vol. 32, No. 11-12, 2007, pp. 1115-1124. http://dx.doi.org/10.1007/s00170-006-0429-2

[22] V. Marinković and M. Madić, "Optimization of Surface Roughness in Turning Alloy Steel by using Taguchi Method," Scientific Research and Essays, Vol. 6, No. 16, 2011, pp. 3474-3484.

[23] P. J. Ross, “Taguchi Techniques for Quality Engineering,” McGraw-Hill International Book Company, Columbus, 1996. 